\title{
Ketamine Anesthesia for Maintenance of Spontaneous Breathing during Video-Assisted Thoracic Surgery
}

\author{
Seong Ho Park, Jong Hoon Yeom \\ Department of Anesthesiology and Pain Medicine, Hanyang University Guri Hospital, Guri, Korea
}

\begin{abstract}
If you have conventional general anesthesia using muscle relaxants for video-assisted thoracic surgery, one lung ventilation with double lumen tube could be dangerous when residual lung volume of non-operated lung could be lacking, and positive pressure ventilation for maintenance of proper minute ventilation could be impossible when there could be too much air leakage. Also, if the abnormal bleeding tendency is, thoracic epidural anesthesia for maintenance of spontaneous breathing could be difficult to perform. A 66-year-old male with a consolidative lesion in involving right middle and lower lobe, and left pneumothorax and pleural effusion successfully underwent video-assisted thoracic bullectomy using ketamine with remifentanil for maintenance of spontaneous breathing and intermittent positive pressure support ventilation within $10 \mathrm{cmH}_{2} \mathrm{O}$ for protection of excessive air leakage.
\end{abstract}

Keywords: Ketamine; Remifentanil; Video-assisted thoracic surgery

\section{INTRODUCTION}

In recent years, studies on anesthesia for thoracic surgery for the prevention of ventilator-associated lung injury (VALI) and intubation-associated complications have been actively conducted, like awake video-assisted thoracic surgery (VATS) with regional analgesia [1] or monitored anesthesia care (MAC) [2]. However, these alternatives are not always available and have some limitations and complications. VATS under general anesthesia without the use of muscle relaxants, using ketamine with remifentanil for maintenance of spontaneous breathing, was successfully performed.

\section{CASE REPORT}

A 66-year-old male with bodyweight $51 \mathrm{~kg}$ visited the hospital with left chest wall pain. In medical history, he had diabetes mellitus and chronic obstructive pulmonary disease. Chest computed tomography revealed right middle lobe and right lower lobe dense consolidation and left hydro-pneumothorax. Bronchoscopy was performed for the possibility of lung cancer in right lower lobe mass and small cell lung cancer was diagnosed. During chemotherapy, there was no acute complication but left pneumothorax and pleural effusions were increased (Fig. 1). Closed thoracotomy was performed but there was still massive air leakage for more than 7 days. He was scheduled for VATS bullectomy for a better life.

In the arterial blood gas analysis (ABGA) before surgery, $\mathrm{pH}$ was 7.31; partial pressure of carbon dioxide $\left(\mathrm{PaCO}_{2}\right)$ was $49.5 \mathrm{~mm} \mathrm{Hg}$; partial pressure of oxygen $\left(\mathrm{PaO}_{2}\right)$ was $70.4 \mathrm{~mm} \mathrm{Hg}$; $\mathrm{HCO}_{3}$ - was $25.1 \mathrm{mM} / \mathrm{L}$; and arterial saturation of oxygen $\left(\mathrm{SaO}_{2}\right)$ was $91.9 \%$ on $\mathrm{O}_{2}$ inhalation $3 \mathrm{~L} / \mathrm{min}$ via nasal prong. In the blood test, prothrombin time (PT, international normalized ratio) was 1.36; PT 63\%; activated partial thromboplastin time was 32 seconds, and platelet count was $390,000 / \mathrm{mm}^{3}$. Echocardiogram revealed severely decreased left ventricular systolic function with ejection fraction $32 \%$; global hypokinesia; aortic valve regurgitation grade 1; mitral valve regurgitation grade 1; and pulmonary artery pressure $33 \mathrm{~mm} \mathrm{Hg}$.

If we have conventional general anesthesia using muscle relaxants, one lung ventilation (OLV) with double lumen tube (DLT) could be dangerous because residual lung volume of the right lung could be lacking. In the case of two lung ventilation (TLV), positive pressure ventilation for maintenance of proper minute ventilation could be impossible because there could be too much air leakage via the left lung. Therefore, we should consider the anes- 


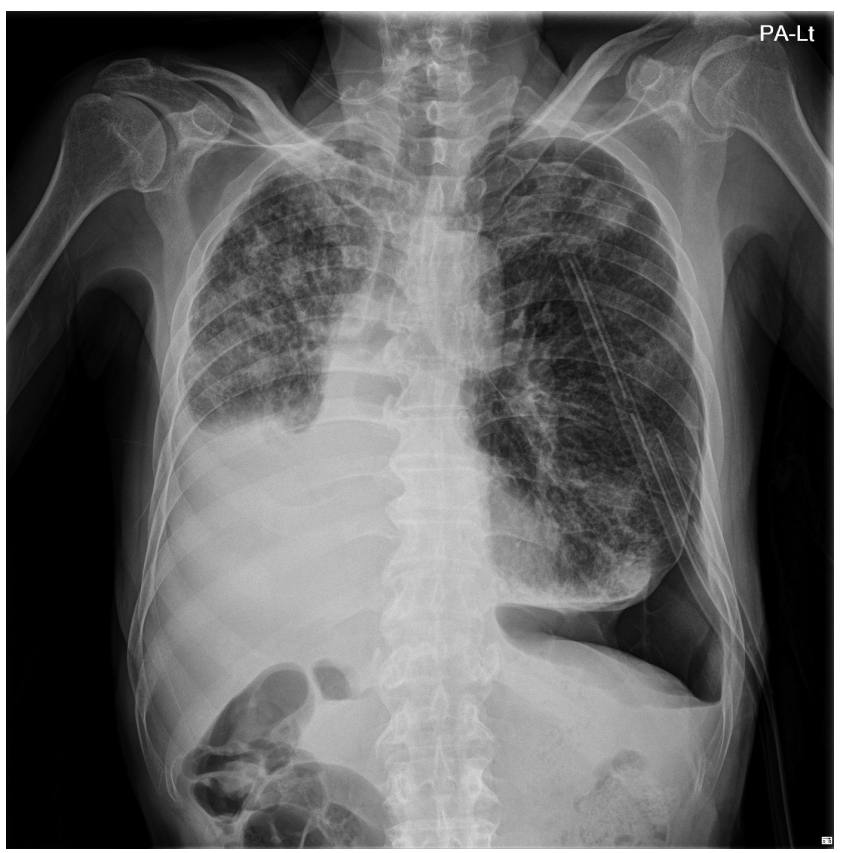

Fig. 1. Preoperative chest $\mathrm{X}$-ray. Consolidative lesion in involving right middle and lower lobe, and left pneumothorax and pleural effusion were observed. PALt, posterior-anterior left.

thetic method for spontaneous breathing. Thoracic epidural anesthesia was difficult to perform because of the result of the abnormal coagulation test, poor cardiac, and respiratory function.

Ketamine is an anesthetic that has effect as a bronchial smooth muscle relaxant and a profound analgesic. Also, unlike propofol or barbiturates, the effect on the central respiratory drive is minimal as shown by an unchanged response to carbon dioxide. So, ketamine could be a good choice for the maintenance of spontaneous breathing during anesthesia. Thus, we planned to do the surgery under DLT intubation and ketamine anesthesia for spontaneous breathing with intermittent positive pressure support (PPS) ventilation within $10 \mathrm{cmH}_{2} \mathrm{O}$. Written informed consents were obtained.

No premedication was given. Upon arrival at the operating room, his heart rate was 115 beats/min, noninvasive blood pressure was $145 / 90 \mathrm{~mm} \mathrm{Hg}$, and respiration rate was above 20 times/min. After denitrogenation with $100 \%$ oxygen, midazolam $2 \mathrm{mg}$, ketamine $60 \mathrm{mg}, 1 \%$ lidocaine $70 \mathrm{mg}$, and remifentanil $4 \mu \mathrm{g} / \mathrm{kg} / \mathrm{hr}$ were administered. After the confirmed loss of consciousness, endotracheal intubation was performed with 37F DLT (Covidien, Mansfield, MA, USA) with McGrath Series (Aircraft Medical, Edinburgh, UK) and there were not cough reflex or significant respiratory depression. Anesthesia was maintained with oxygen $4.0 \mathrm{~L} / \mathrm{min}$, ketamine 1.8
$2.4 \mathrm{mg} / \mathrm{kg} / \mathrm{hr}$, and remifentanil 1.0-4.0 $\mu \mathrm{g} / \mathrm{kg} / \mathrm{hr}$ for abolishing both somatic and visceral pain. Ventilation was maintained by the patient's self-breathing with manual bagging at pop-off valve pressure $10 \mathrm{cmH}_{2} \mathrm{O}$ as needed. The patient's oxygen saturation by pulse oximeter $\left(\mathrm{SpO}_{2}\right)$ remained between $99 \%$ and 100\% during TLV. Because OLV with right lung could not maintain $\mathrm{SpO}_{2}$ above $90 \%$, the operation was performed under TLV and bispectral index score was maintained between 40 and 80 during operation. During operation, there were no significant hemodynamic changes, $\mathrm{SpO}_{2}$ was maintained above 95\%, end-tidal $\mathrm{CO}_{2}$ concentrations below $50 \mathrm{~mm} \mathrm{Hg}$ were maintained. Extubation was done after spontaneous, regular breathing and proper tidal volume above $5 \mathrm{~mL} / \mathrm{kg}$ were confirmed. He was transferred to the post-anesthesia care unit (PACU).

During his stay at the PACU, he kept nasal prong $4 \mathrm{~L} / \mathrm{min}$ for oxygenation, $\mathrm{SpO}_{2}$ above $95 \%$ was maintained, and vital signs were stable. Thirty minutes after arrival at PACU, ABGA was confirmed that $\mathrm{pH}$ was 7.28; $\mathrm{PaCO}_{2}$ was $59.7 \mathrm{~mm} \mathrm{Hg} ; \mathrm{PaO}_{2}$ was $107.4 \mathrm{~mm} \mathrm{Hg}$; $\mathrm{HCO}_{3}$ - was $28.3 \mathrm{mM} / \mathrm{L}$; and $\mathrm{SaO}_{2}$ was $97.2 \%$. We changed $\mathrm{O}_{2}$ inhalation from nasal prong $4 \mathrm{~L} / \mathrm{min}$ to $3 \mathrm{~L} / \mathrm{min}$. Thirty minutes later, in the ABGA, pH was 7.32; $\mathrm{PaCO}_{2}$ was $53.1 \mathrm{~mm} \mathrm{Hg} ; \mathrm{PaO}_{2}$ was $100.1 \mathrm{~mm} \mathrm{Hg} ; \mathrm{HCO}_{3}$ - was $27.5 \mathrm{mM} / \mathrm{L}$; and $\mathrm{SaO}_{2}$ was $97.0 \%$. $\mathrm{He}$ was discharged from PACU and moved to the general ward after consciousness came back.

\section{DISCUSSION}

OLV via DLT or bronchial blocker with VATS is known as the golden standard for treating pneumothorax. However, these conventional general anesthesia methods using muscle relaxants may induce VALI and intubation-associated complications. VALI is one of the major concerns in general anesthesia [3]. The ventilator can cause a variety of inflammatory reactions and eventually cause decreased compliance, ventilation-to-perfusion mismatch, loss of surfactant, and interstitial edema [4]. Also, acute lung injury can be caused by VALI in patients with previous lung disease. It is reported about $4 \%$ of patients who undergo major lung resections $[5,6]$ and a mortality rate is up to $25 \%$. These side effects can be avoided if the patient keeps spontaneous breathing without a ventilator.

Recently, other anesthesia methods are applied and studies are actively being conducted. Awake thoracic surgery with local or regional analgesia techniques or MAC without intubation has been 
studied to avoid complications related to conventional general anesthesia [2,7]. These anesthetic methods have been successfully employed to pneumothorax, emphysema, or even oncologic conditions like peripheral lung nodules and mediastinum tumors.

Awake VATS can avoid many complications associated with OLV, like VALI and OLV related injury [8]. Thoracic epidural analgesia (TEA), intercostal nerve block, or paravertebral block can be used for awake VATS. In most cases, TEA is used for regional anesthesia because sufficient analgesic effect can be obtained with TEA alone. Several meta-analyses showed reduction of pulmonary complications and decrease systemic stress response to surgery and reduced opioid consumption after epidural analgesia.

However, the high thoracic epidural block may be associated with a reduction of respiratory function as a result of the motor block of intercostal muscles [9], and hypotension and bradycardia may occur [10]. Unexpected large dose intrathecal injection of local anesthetics may cause complications like hypotension, apnea, and unconsciousness. Also, epidural hematoma, direct spinal cord trauma, and epidural abscess can make severe neurological complications like permanent paraplegia.

Although awake VATS with TEA is suggested as a good alternative replacing conventional general anesthesia methods using muscle relaxants, there are some cases that make it difficult to apply and the benefits remain unclear. The selection of the anesthesia methods should be made considering the potential problems including the patient's underlying condition and operative procedure before the surgery. Awake state and supraglottic airway could avoid intubation-associated complications, but there might be difficulties in the removal of tracheal secretions and airway management. DLT may be preferable over the single lumen tube for the protection of non-operated lung.
The anesthesiologist should choose an anesthetic method that minimizes the risks to the patient before surgery and be familiar with various anesthetic methods. Like this case, if spontaneous breathing should be needed but TEA can't be applied, anesthetic management using ketamine with remifentanil for spontaneous breathing with intermittent PPS ventilation below $10 \mathrm{cmH}_{2} \mathrm{O}$ may be a good alternative.

\section{REFERENCES}

1. Park SY. Non-intubated thoracic surgery under thoracic epidural anesthesia. Korean J Anesthesiol 2017;70:235-6.

2. Nezu K, Kushibe K, Tojo T, Takahama M, Kitamura S. Thoracoscopic wedge resection of blebs under local anesthesia with sedation for treatment of a spontaneous pneumothorax. Chest 1997;111:230-5.

3. Belperio JA, Keane MP, Lynch JP 3rd, Strieter RM. The role of cytokines during the pathogenesis of ventilator-associated and ventilator-induced lung injury. Semin Respir Crit Care Med 2006;27:350-64.

4. Pavone LA, Albert S, Carney D, Gatto LA, Halter JM, Nieman GF. Injurious mechanical ventilation in the normal lung causes a progressive pathologic change in dynamic alveolar mechanics. Crit Care 2007;11:R64.

5. Licker M, Fauconnet P, Villiger Y, Tschopp JM. Acute lung injury and outcomes after thoracic surgery. Curr Opin Anaesthesiol 2009;22:61-7.

6. Licker M, de Perrot M, Spiliopoulos A, Robert J, Diaper J, Chevalley C, et al. Risk factors for acute lung injury after thoracic surgery for lung cancer. Anesth Analg 2003;97:1558-65.

7. Liu J, Cui F, Li S, Chen H, Shao W, Liang L, et al. Nonintubated videoassisted thoracoscopic surgery under epidural anesthesia compared with conventional anesthetic option: a randomized control study. Surg Innov 2015;22:123-30.

8. Asai T, Koga K, Vaughan RS. Respiratory complications associated with tracheal intubation and extubation. Br J Anaesth 1998;80:767-75.

9. Kochi T, Sako S, Nishino T, Mizuguchi T. Effect of high thoracic extradural anaesthesia on ventilatory response to hypercapnia in normal volunteers. Br J Anaesth 1989;62:362-7.

10. Wattwil M, Sundberg A, Arvill A, Lennquist C. Circulatory changes during high thoracic epidural anaesthesia: influence of sympathetic block and of systemic effect of the local anaesthetic. Acta Anaesthesiol Scand 1985;29:849-55. 